\title{
As diferenças étnico-raciais no currículo da escola: análise intercultural crítica e decolonial
}

\section{Ethnic and racial differences in the school curriculum: intercultural critic and decolonial analyses}

\section{RESUMO}

O artigo tem como objetivo analisar como se dá a discussão das relações étnico-raciais em escolas avaliadas com baixo Índice de Desenvolvimento da Educação Básica (IDEB). Inscreve-se na interculturalidade crítica e na perspectiva decolonial, campos teóricos que questionam os processos de hierarquização e subalternização baseados na racialização dos seres humanos. Para a produção dos dados, foram entrevistados professores de escolas básicas com baixo IDEB de Mato Grosso do Sul. Os resultados indicaram que todos os professores reconhecem a existência do racismo, a necessidade de superá-lo e a importância de fazer a discussão das relações étnico-raciais no currículo; portanto, há potência intercultural crítica e decolonial em suas reflexões.

Palavras-chave: Currículo; Interculturalidade crítica; Decolonialidade.

\begin{abstract}
This paper aims to analyze how ethnic and racial relations have been approached in schools evaluated with low Basic Education Development Index (IDEB). It is grounded on both the critical interculturality approach and the decolonial perspective, theoretical fields that have questioned the processes of hierarchization and subalternization based on the racialization of human beings. Data were obtained from interviews with teachers working in basic education schools with low IDEB in the state of Mato Grosso do Sul. Results have shown that all the teachers acknowledge the existence of racism, the need to overcome it, and the importance of discussing ethnic and racial relations in the curriculum; hence, their reflections have evidenced intercultural critical and decolonial potency.
\end{abstract}

Keywords: Curriculum; Critical interculturality; Decoloniality.

\section{INTRODUÇÃO}

Este artigo é fruto de duas pesquisas: uma em nível de doutoramento em Educação e outra financiada pelo CNPq (Edital Produtividade 2017). Como as duas pesquisas tiveram como foco a questão étnicoracial no currículo da escola, foi possível escrever este artigo com o objetivo de analisar como se dá a discussão das relações étnico-raciais em escolas avaliadas com baixo Índice de Desenvolvimento da Educação Básica (IDEB). Optou-se pelas escolas de baixo IDEB porque costumam ser malvistas

\footnotetext{
${ }^{1}$ FECRA - Faculdade de Costa Rica, Costa Rica/MS - Brasil.

2 UCDB - Universidade Católica Dom Bosco, Campo Grande/MS - Brasil.
} 
na ótica do neoliberalismo, mas a intenção do artigo é mostrar que nessas escolas há potência intercultural crítica e decolonial.

Foram entrevistados mais de 30 professores de quatro escolas da Rede Estadual de Mato Grosso do Sul, todas com baixo IDEB, mas neste artigo faremos menção a apenas seis deles. As entrevistas foram utilizadas como meio de obtenção dos dados por entendermos, com Bogdan e Biklen (1994, p. 136), que as "[...] boas entrevistas produzem uma riqueza de dados, recheados de palavras que revelam as perspectivas dos respondentes".

Argumenta-se que refletir sobre as possibilidades de discussão das relações étnico-raciais implica pensar a construção de uma escola com um currículo a partir das perspectivas intercultural crítica e decolonial. Essas perspectivas questionam/tensionam o modelo de sociedade historicamente construído, assentado em padrões monoculturais e valores hegemônicos brancos, machistas, cristãos e europeus, entre outros. Implicam, ainda, reconhecer que a sociedade é marcada pela diversidade cultural, racial e sexual, entre outras, o que desafia cotidianamente a escola. A partir do currículo monocultural predominante em grande parte das escolas, inclusive nas escolas onde os professores entrevistados atuam, somos instigados a conhecer e a problematizar as situações e práticas, no sentido de construir um conjunto de estratégias pedagógicas que respondam democraticamente à condição plurirracial da sociedade brasileira para que se percebam as diferenças, "o outro" como vantagem pedagógica (CANDAU, 2011).

\section{SITUANDO A ANÁLISE}

Como destacamos, as perspectivas de análise são a da interculturalidade crítica e a da decolonialidade. Tanto uma como a outra se propõe ir além dos questionamentos e tensionamentos. Elas se preocupam, sobretudo, com a "[...] exclusión, negación y subalternización ontológica y epistémico-cognitiva de los grupos y sujetos racializados por las prácticas - de deshumanización y subordinación de conocimientos - que privilegian a unos sobre otros, naturalizando la diferencia y ocultando las desigualdades" (WALSH, 2010, p. 91).

Ambas buscam a construção de uma sociedade a partir e com os sujeitos historicamente subalternizados, o que significa uma desconstrução dos currículos e das práticas educativas predominantes nas escolas. Com o propósito de avançar em direção à educação intercultural, Santiago, Akkari e Marques (2013, p. 27) propõem a necessária construção de "uma pedagogia que afirme a diferença em seus aspectos históricos-políticos-sociais e de poder". Olivencia (2016, p. 50) enfatiza que a educação intercultural "[...] es la propuesta educativa inclusiva que favorece 0 conocimiento y el intercambio cultural, así como la valorización positiva de la diversidad cultural en términos de convivencia, innovación curricular y fomento de la participación comunitaria".

Nas perspectivas da interculturalidade crítica e da decolonialidade, a diferença não é vista apenas como algo que constitui os povos em suas singularidades, assentada na matriz cultural; prioriza-se o questionamento do uso da diferença como projeto de dominação, inferiorização e subalternização do outro - no caso desta pesquisa, dá-se ênfase à questão racial. Como aponta Quijano (2005, p. 227), a racialização e, portanto, a raça são "[...] uma construção mental que expressa a experiência básica da dominação colonial e que desde então permeia as dimensões mais importantes do poder mundial, incluindo sua racionalidade específica: o eurocentrismo". 
Na escola e nos currículos, é importante visibilizar a diferença como possibilidade de aprendizagem de conhecimentos outros e de transformações. A diferença, nesse contexto, é ferramenta pedagógica para a construção de uma sociedade "outra", o que, em conformidade com Walsh (2010, p. 93), significa não apenas

[...] uma práxis pedagógica crítica, intercultural y de-colonial que pretende pensar no sólo desde as luchas de los pueblos históricamente subalternizados, sino también com sujetos, conocimientos y modos distintos de estar, ser y vivir, dando un giro a la unicidade y monoculturalidad fundantes de la empresa educativa y su razón modernooccidental-capitalista, para dar centraldad, mas bien, a la vida y, por ende, al trabjo aún incompleto de la humanización y descolonización.

Trata-se de uma educação que questiona a lógica monocultural, âncora da lógica capitalista de dominação e exploração, reconhecendo e valorizando as diferenças, com o propósito de fortalecer os processos de ensino e aprendizagem por meio da inserção de conhecimentos "outros", construídos com e pelos diferentes grupos culturais até então marginalizados e subalternizados. Isso é fundamental para a construção de uma sociedade com justiça social, além de melhorar em muito a aprendizagem dos alunos, haja vista que uma pesquisa realizada pela Fundação Instituto de Pesquisas Econômicas de São Paulo constatou, conforme afirma Vera Candau em entrevista concedida a Carvalho e Pletsh (2011, p. 281), "[...] na análise e na comparação dos dados que, quanto maiores eram os índices de preconceito e discriminação, menores eram as médias de aproveitamento dos estudantes".

O projeto de construção de uma educação que tenha como suporte o diálogo intercultural crítico e a decolonialidade constitui ainda um desafio, posto que a questão étnico-racial continua invisibilizada, assim como a da justiça social, sobretudo pela lógica do mercado capitalista, que afirma que todos têm as mesmas oportunidades de acesso aos bens materiais e os mesmos direitos humanos. Entretanto, compreendemos que as condições produzidas para acessar as oportunidades são sistematicamente desiguais para os diferentes grupos, com destaque para os negros, em função do período colonial e atualmente em função da colonialidade: "La escalera de gradación entre el 'blanco' de la 'raza blanca' y cada uno de los otros 'colores' de la piel, fue asumida como una gradación entre lo superior y lo inferior en la clasificación social 'racial'"'. (QUIJANO, 2007, p. 120).

Dessa forma, ressaltamos a importância da construção de uma postura que coloca em xeque essa classificação em seres supostamente superiores e seres supostamente inferiores. Também colocamos sob suspeita a ideia de igualdade como homogeneidade e mesmidade. Assim, somos desafiados a refletir sobre nossas próprias fronteiras, a assumi-las e a tensioná-las, considerando que somos constituídos na interação com relações culturais, sociais, políticas e econômicas construídas historicamente. Concordamos com Akkari e Santiago (2015, p. 31) quando afirmam:

A diferença como elemento constituinte do ser humano e a educação como direito assegurado a todo indivíduo nos desafiam a pensar estratégias que possibilitem articular o processo educacional para além das práticas homogeneizadoras presentes no cotidiano escolar e, sobretudo, a superar barreiras impostas pelo preconceito às diferenças.

Reconhecer a importância da escola na construção, desconstrução, reconstrução e significação dos conhecimentos de seus estudantes, com ênfase nos conhecimentos dos negros, implica pensar estratégias para a construção de relações problematizadoras e tensionadoras das questões relacionadas às diferenças no seu interior, bem como para o compromisso de desafiar as práticas que 
resultam em hierarquização das diferenças. Diante disso, novas exigências são postas para a formação de professores, que, como Santiago, Akkari e Marques (2013, p. 43) afirmam, têm "[...] importante papel como mediador[es] na construção de relações interculturais positivas [...]" e para que os mesmos aprendam a lidar com as diferenças presentes na sala de aula como constitutivas dos seres humanos, comprometidos com a "[...] negociação e o diálogo com as diferenças e os conflitos oriundos delas" (p.43), deixando de percebê-las como anomalias, como males a serem corrigidos.

Considerar as diferentes culturas, neste artigo, especialmente a cultura negra e os seus conhecimentos que permeiam o currículo, é fundamental. Além disso, para que a diferença seja valorizada como recurso, ferramenta pedagógica potencializadora do ensino e aprendizagem, faz-se necessária a construção de pontes no currículo para que a interação, a mediação, a troca e o entrelaçar de conhecimentos sejam possíveis, sem privilegiar uma cultura em detrimento da outra. Nesse sentido, importa trazer o que se entende por currículo.

As teorias do currículo estão preocupadas em buscar respostas para as questões que desafiam o contexto educacional constantemente: quais conteúdos devem ser ensinados aos estudantes? Por que estes e não outros conteúdos? Qual o melhor momento para ensinar este ou aquele conteúdo? A quem interessam os conteúdos ensinados na escola? Como afirmam Moreira e Silva, o "[...] currículo corresponde, assim, tanto a uma questão de conhecimento quanto a uma questão de identidade" (2011, p. 7).

Considerando currículo como um campo polissêmico de disputa de poderes e intenções, nunca estático, pontuamos a centralidade cultural para discutir a questão étnico-racial nos currículos. Segundo Pacheco (2005, p. 37), "[...] o currículo é uma prática pedagógica que resulta da interacção e confluência de várias estruturas (políticas/ administrativas, econômicas culturais, sociais, escolares...) na base das quais existem interesses concretos e responsabilidades compartilhadas".

Portanto, o currículo é um campo de disputas e, como tal, não tem a inocência ou a neutralidade afirmada nas teorias tradicionais, isto é, o currículo está sempre a serviço de algo ou alguém - como afirma Pacheco (2005), há interesses concretos. Por isso, o currículo escolar é o lócus adequado para tensionar as práticas monoculturais na escola, na intenção de construir um currículo intercultural crítico e decolonial que perceba as diferenças como diferenças, e não como desigualdades. Conforme pontua Ramos, "[...] é possível perceber no interior da escola, a partir de suas ambiguidades, contradições que permeiam o todo social, tornando possível um trabalho crítico transformador na própria escola" (2011, p. 76).

As questões relacionadas a racismo e preconceito na sociedade como um todo, e principalmente no interior da escola, estão entremeadas em todos os conflitos escolares e, em grande parte, a partir de nossa experiência como educadores, são imperceptíveis no cotidiano da escola, sendo visibilizadas em momentos específicos, como a semana da "Consciência Negra". Isso caracterizaria o que Santomé (1995) denomina de currículo turístico, em que as problemáticas são discutidas ocasionalmente, não fazendo parte do projeto da escola como um todo.

Na ótica da interculturalidade crítica e decolonial, a discussão sobre a igualdade no currículo passa por vários questionamentos, sendo que, se considerarmos o direito à igualdade de acesso à educação escolarizada, poderemos verificar que o acesso é parcialmente assegurado, mas as condições de permanência ainda estão longe de ser garantidas, haja vista os índices de evasão e retenção, 
justificados, em grande parte, por questões sociais: famílias denominadas de desestruturadas, alimentação inadequada, questões de afetividade, inaptidão do estudante, etc. Concordamos com Ramos, que afirma que ainda estamos procurando explicar os problemas da escola a partir da falta, assim desconsiderando toda a complexidade que envolve o processo educativo e transformando o fracasso em "[...] uma questão de desempenho de alunos e/ou professores, que, ao não serem capazes de corresponder ao investimento educativo, frustram a possibilidade de alcance de uma sociedade igualitária que a escolarização promete" (RAMOS, 2011, p. 70).

Importa reconhecer a complexidade da educação, questionando radicalmente os múltiplos aspectos monoculturais e da colonialidade do currículo. Não mais é possível considerar as diferenças culturais de maneira superficial, trivializada; somos desafiados a pensar o currículo a partir das diferenças dos alunos.

Moreira e Silva (2011) afirmam que o currículo está sempre envolto nas relações de poder. Como questão central nas relações de poder, é um campo de construção, desconstrução, significação e ressignificação de sentidos e valores, um espaço de lutas e possibilidades para a construção de uma educação pautada na igualdade de direitos.

Cada vez mais, faz sentido pensar a educação e o currículo a partir da perspectiva intercultural crítica e decolonial para a construção de um tempo espaço em que seja possível o diálogo entre diferentes saberes, diferentes culturas, como um veículo de articulação da diferença com a igualdade de direitos no processo de construção constante de sujeitos que possam viver sua diferença sem serem vistos como inferiores.

Assim, considerando que o currículo é uma construção social, intencional, resultado de lutas pelo poder, lembramos que as questões raciais não podem ficar ausentes, que os diferentes grupos raciais devem estar presentes na discussão sobre sua construção. Isso porque o currículo está permeado por questões culturais que não são neutras; cada grupo deve dialogar para que suas práticas culturais sejam aí significadas e empoderadas.

Reiteramos a necessidade da transformação da escola e do currículo com base na interculturalidade crítica e decolonial para que sujeitos mais democráticos e atentos às diferenças possam construir uma sociedade onde os conflitos não sejam invisibilizados e as mazelas não sejam atribuídas às próprias vítimas - onde o outro possa ser visto por si mesmo, e não a partir do mesmo. Para tanto, é fundamental que no currículo as questões étnico-raciais sejam trabalhadas. Como os professores de escolas com baixo IDEB trabalham com elas é o que passaremos a analisar.

\section{AS RELAÇõES ÉTNICO-RACIAIS EM ESCOLAS COM BAIXO IDEM: UM DIÁLOGO COM OS PROFESSORES}

Iniciamos salientando que, de maneira alguma, culpabilizamos ou responsabilizamos os professores pela forma como concebem e trabalham as relações étnico-raciais. A forma de pensar e trabalhar está relacionada ao contexto no qual fomos produzidos. Todos somos o resultado de um contexto maior, que é a sociedade capitalista, a cultura monocultural e a colonialidade, as quais fazem com que as diferenças étnico-raciais tendam a ser silenciadas, invisibilizadas e discriminadas. Nesse sentido, cabe sublinhar que "a reflexão crítica nos faz sempre privilegiar, na análise, as relações dos 
sujeitos com o seu entorno, não os vendo simplesmente como indivíduos que agem segundo sua vontade individual". (PAVAN; BACKES, 2016, p. 16).

Trazemos por primeiro a fala da professora Marta, que percebe racismo na escola e no currículo, mas afirma que não sabe por que ele ocorre:

E também racial, a gente vê muito em sala de aula. Trabalho em grupo, de não querer juntar com o colega por causa disso. Questão de falar que não consegue, de relacionar a pessoa com a cor, até isso eu já presenciei dentro de sala de aula, tem alunos que falam. Agora, eu não sei como, por que a criança tem isso, eu não descobri ainda, se já veio da família, mas isso existe ainda.

A professora Marta reconhece que há racismo em sala de aula, o que é importante, mas insuficiente na perspectiva da interculturalidade crítica e decolonial. A questão central é justamente aquilo que a professora diz não saber: a causa do racismo. Como apontamos, esse não saber está ligado ao processo histórico e cultural no qual fomos produzidos, que não nos faz perceber que o racismo foi construído como estratégia de dominação e exploração do capitalismo, como sistematicamente evidenciam os estudos da decolonialidade. O campo de investigação da colonialidade "[...] vincula el proceso de colonización de las Américas y la constitución de la economía-mundo capitalista como parte de un mismo proceso histórico [...]". (CASTRO-GÓMEZ; GROSFOGUEL, 2007, p. 19). Reconhecer essa relação, trazê-la para o currículo das escolas, é central na ótica da interculturalidade crítica.

Observamos, pela entrevista realizada, que a professora Marta é afetada pela percepção de diferenças e desigualdades nas relações tecidas no contexto escolar que promovem a inferiorização dos denominados diferentes por meio de deboches e brincadeiras que excluem o outro. Ela reconhece a necessidade de discutir os processos discriminatórios em sala de aula, no sentido de respeitar e valorizar as diferenças, mas, por não saber a história da construção do racismo, sensibilizada com a dor provocada pelo racismo e discriminação, recorre ao discurso cristão, dizendo que sempre fala para os alunos que: "perante Deus, nós somos todos iguais, por debaixo da pele, o sangue é da mesma cor, do mesmo lugar de onde você saiu é para onde você vai voltar, é, nós somos todos do mesmo jeito".

A fala da professora, embora denote a preocupação em tentar evitar a discriminação em sala de aula, demonstra uma compreensão essencialista ("perante Deus, nós somos todos iguais") e biologicista ("debaixo da pele, o sangue é da mesma cor") da diferença, o que se afasta radicalmente de uma proposta intercultural crítica e decolonial, que propõe justamente romper com a essencialização e a naturalização da diferença e mostrar, discutir, problematizar seu caráter histórico, as relações de poder presentes em todas as relações sociais. Ou seja, a fala da professora expressa a necessidade de a escola repensar o currículo para inserir discussões sobre as diferenças, indo além de argumentos que, ao invés de romper com processos discriminatórios, os fortalecem. Somente com uma compreensão politizada da diferença, isto é, de que todas as relações sociais estão atravessadas por relações de poder, neste mundo, e não "perante Deus", o processo curricular pode acontecer sem associar as diferenças à inferioridade, mas como formas legítimas de ser, viver, conhecer e estar no mundo.

A professora Vanda reconhece as diferenças, mas ainda sente dificuldades em lidar com elas, afirmando que procura trabalhar com diferentes tipos de aula e que, às vezes, insere a discussão sobre as diferenças: "agora, o que sinto mais dificuldade é quando a gente percebe que na sala de 
aula tem o aluno que tem certa forma de preconceito, e você tem que trabalhar isso sem afetar o outro que está na sala". Isso evidencia que tal discussão não pode acontecer sem que haja a sensibilização para acolher o outro. A professora argumenta que já presenciou situações discriminatórias na sala de aula e que, na hora, agiu como se não tivesse percebido, mas que, depois do ocorrido, chamou em particular o aluno que havia praticado a discriminação e conversou com ele, mostrando que ele havia desrespeitado o colega.

Novamente, há de se destacar que a professora procura evitar a discriminação e o racismo na sala de aula, mas a forma escolhida acaba contribuindo pouco. Ainda que tenha preocupação em não expor o aluno e o chame para conversar individualmente, essa prática acaba reforçando que o racismo é uma questão individual (entre um indivíduo que discrimina e um indivíduo que é discriminado), e não um produto histórico e cultural. Nas perspectivas intercultural crítica e decolonial, esses temas assumem uma dimensão coletiva. A ideia de que é melhor "fingir que não percebeu" o racismo na sala e conversar individualmente com o aluno tem a ver com duas características amplamente apontadas pelos pesquisadores do campo étnico-racial: a ideologia do branqueamento e o mito da democracia racial. Conforme Santiago, Akkari e Marques, "[...] o racismo brasileiro historicamente se apresentou de forma silenciosa e dissimulada em função dos processos de branqueamento e pelo mito da democracia racial assimilado no imaginário social da população brasileira" (2013, p. 120).

Diferentemente da professora Vanda, a professora Mirna mostra que faz a discussão de forma coletiva na sala de aula:

\begin{abstract}
Eu acho que já. Tem a ver com a questão da cor de pele, a pele negra, a questão do cabelo. Na sala em que a gente tem diferentes orientações sexuais a gente percebe também esse preconceito. [...] Com certeza. Interfiro de uma maneira que não venha expor o aluno ainda mais, mas que... Tentando trazer uma consciência para a turma, para a sala, de que cada um é diferente do outro mesmo e que todas as diferenças devem ser respeitadas. [...] Eu acredito que não pelo indivíduo em si, mas talvez pelo meio, da maneira que o meio se comporta em relação a esse indivíduo diferente. Porque o aluno começa a se sentir acuado, envergonhado, e isso vai se refletir na aprendizagem dele, com certeza.
\end{abstract}

Nessa fala, como já destacado, observa-se que a professora faz a discussão coletiva, o que é muito importante nas perspectivas intercultural crítica e decolonial, pois contribui para mostrar que as relações são sociais e produzidas culturalmente. Além disso, a professora diz ter o cuidado de não expor mais ainda o aluno discriminado, mostrando a existência das diferenças como algo positivo. Observa-se, ainda, um terceiro elemento importante, que é a percepção de que o aluno discriminado fica acuado, não por um problema dele, mas porque o meio, o contexto, vai produzindo a subjetividade. Isso significa que há um "exterior constitutivo" (HALL, 2003) que produz a subjetividade; portanto, para que o sujeito não fique acuado, é preciso modificar as relações sociais entre os alunos que produziram aquela situação. Isso é fundamental, pois, como afirma Candau (2016, p. 816), não trabalhar a diferença de forma positiva produz "[...] baixa autoestima, elevados índices de fracasso escolar e multiplicação de manifestações de desconforto, mal-estar e agressividade em relação à escola".

O professor Luiz também traz uma compreensão das diferenças que se aproxima das perspectivas intercultural crítica e decolonial.

As diferenças são gritantes e inúmeras. Tem aí desde as diferenças étnico-raciais, diferenças sociais e familiares. É gritante isso na sala de aula. Na verdade, se 
encontram dentro da sala de aula, e isso muitas vezes gera muitos conflitos. Então, por isso que eu falei, na pergunta anterior, da questão do tempo, para você adaptar o currículo a essas realidades. Eu tenho várias situações dentro da sala de aula que eu tenho que trabalhar; além de trabalhar o currículo, eu tenho que trabalhar isso, saber trabalhar isso, o respeito entre essas diferenças, não acabar com as diferenças, as diferenças não vão se acabar, mas sim fazer com que sejam respeitadas dentro de sala de aula.

Embora o professor faça uma distinção do currículo que ele deve trabalhar, entendido por ele como os conteúdos das disciplinas - e o currículo não se resume a isso nas perspectivas intercultural crítica e decolonial -, há em sua reflexão elementos importantes nas óticas intercultural crítica e decolonial: primeiro, ele reconhece que há muitas diferenças em sua sala de aula, fugindo da ideia ainda existente de que na sala de aula todos são iguais; segundo, ele precisa trabalhar essas diferenças, não pode "fingir" que elas não existem; terceiro, as diferenças geram conflitos, portanto, há relações de poder; e, por último, talvez o mais importante, o objetivo não é acabar com as diferenças, mas aprender a conviver com elas. Pode-se dizer que a fala do professor vem ao encontro do pensamento de Candau (2008, p. 52), que escreve:

A perspectiva intercultural que defendo quer promover uma educação para o reconhecimento do "outro", para o diálogo entre os diferentes grupos sociais e culturais. Uma educação para a negociação cultural, que enfrenta os conflitos provocados pela assimetria de poder entre os diferentes grupos socioculturais nas nossas sociedades e é capaz de favorecer a construção de um projeto comum, pelo qual as diferenças sejam dialeticamente integradas.

Outros professores ainda estão com mais dificuldade de trabalhar com as diferenças e de compreendê-las mais em consonância com as óticas da interculturalidade crítica e decolonial. A professora Lúcia afirma que a questão das diferenças está cada vez mais presente no contexto escolar, mas, quando indagada sobre como trabalha com as diferenças, apresenta certa ambiguidade na compreensão das diferenças, afirmando: "eu falo para eles que não existe diferença, não existe diferença de cultura". No entanto, mais adiante, a professora diz que explica para as crianças "que um tem que conhecer a cultura do outro e trabalhar e aceitar o jeito que a pessoa vive, a maneira dele de viver, a maneira dele de falar. Igual o nordestino que vem para cá; ele fala de maneira diferente, nós temos que nos acostumar". A professora mostra sensibilidade para com as diferenças e denota nuances de práticas voltadas para a interculturalidade crítica. A professora expressa a dificuldade, os avanços e as fragilidades que temos no âmbito da escola (e também da sociedade) de entender as diferenças como vantagem pedagógica. A ambiguidade de suas falas mostra seu receio de que a diferença seja entendida como inferioridade quando diz que "não existe diferença de cultura". Por outro lado, a diferença salta, invade, ocupa todos os lugares em sala de aula, daí a afirmação: "temos que nos acostumar". Embora isso fique muito próximo da simples tolerância, percebe-se a preocupação da professora em fazer com que os alunos se sintam acolhidos na escola. A docente expressa o momento de tensão que vivemos na escola: de um lado, a lógica monocultural engessando as concepções; de outro, o dia a dia mostrando sua multiculturalidade.

A ambiguidade da professora Lúcia está relacionada a uma discussão central nos campos da interculturalidade crítica e da decolonialidade: a necessária articulação entre diferença e igualdade, vendo ambas como condição de possibilidade para a construção da justiça social. Nesse sentido,

Uma proposta de educação que considere a pluralidade de valores, de tempos e ritmos não se limita em introduzir, na prática educativa, novos conteúdos e novos materiais didáticos. Mas compreende que tratamento igual não significa tratamento 
homogeneizante, que apaga as diferenças. A promoção da igualdade significa dialogar com a diferença. Enquanto a diferença for um obstáculo para o êxito escolar, não haverá reconhecimento às diferenças, mas produção e reprodução das desigualdades. (AKKARI; SANTIAGO, 2015, p. 35).

Portanto, uma educação que tenha como suporte a interculturalidade crítica e a perspectiva decolonial, que questione e articule igualdade e diferença, constitui ainda um desafio porque implica romper com a ideia de diferença como inferioridade e subalternidade. Se as oportunidades existem, as condições produzidas para acessá-las são diferentes para os diferentes grupos. Ressaltamos a importância de colocar suspeita a ideia de igualdade como homogeneidade e mesmidade. Somos desafiados a refletir, assumir e tensionar nossas próprias fronteiras, considerando que somos constituídos na interação com relações culturais, sociais, políticas e econômicas construídas historicamente.

Segundo Candau (2011), é importante que nas escolas haja a compreensão de que a igualdade e a diferença devem ser buscadas conjuntamente. A autora aponta que seria importante que a igualdade e a diferença estivessem presentes nos projetos pedagógicos: "algo que impregna o projeto político pedagógico dos cursos e que defende a tese que uma escola democrática tende a articular igualdade com diferença. Uma escola que reconheça as diferentes culturas presentes no seu contexto". (CANDAU, 2011, p. 283).

A professora Milena diz que sabe que as questões étnico-raciais não devem ser discutidas apenas em alguns momentos e que devem ser centrais nas escolas:

Eu aprendi, assim, que a gente não trata desses assuntos apenas nessas datas, que às vezes, por exemplo, o dia do índio não é apenas você pintar o menino de índio, caracterizá-lo de índio. Tem que ir além disso, tem que levá-lo a refletir, por exemplo, como que está a população indígena nos dias atuais, como que eles vivem, nesse sentido.

É de fundamental importância o que a professora Milena destaca sob as perspectivas da interculturalidade crítica e decolonial. A discussão precisa ser cotidiana, fazer parte, como afirma Candau (2011), do Projeto Pedagógico da escola. Santomé (2013, p. 170) chama a atenção para o fato de que geralmente as diferenças não são trabalhadas de forma central. Segundo ele, elas costumam ser tratadas "[...] com uma perspectiva muito trivial, similar ao modo como a maioria das pessoas faz turismo; analisando exclusivamente aspectos como sua culinária, seu folclore, suas formas de vestir, seus rituais festivos, a decoração de suas casas, a paisagem".

\section{CONSIDERAÇÕES FINAIS}

Neste artigo, vimos a escola e o currículo sob as perspectivas intercultural crítica e decolonial, que questionam a lógica monocultural e a colonialidade que ainda os marcam. Também pontuamos a escola e o currículo como espaços de possibilidades, encontros, busca, diálogos, tensões e conflitos, nos quais é possível pensar e desenvolver outros currículos, currículos em que se questionem as práticas racistas e discriminatórias e se contribua para a construção da justiça social, que só é possível se articularmos as diferenças com a igualdade. 
Salientamos a necessidade da construção do currículo e da escola intercultural crítica e decolonial para que a escola seja repensada a partir do encontro, do trânsito e da vivência de diferentes culturas - culturas aqui compreendidas não como superiores ou inferiores, apenas diferentes.

Vimos também que todos os professores mostram indícios da potência da interculturalidade crítica e da perspectiva decolonial. Ainda que alguns estejam dando os primeiros passos nessa direção, todos reconhecem a existência do racismo, a necessidade de desconstruí-lo e a importância da discussão das relações étnico-raciais no currículo, o que, considerando a nossa história e cultura colonial, monocultural, bem como a colonialidade, não é pouca coisa. Inspirados em Walsh (2017), podemos dizer que a potência intercultural crítica e decolonial (re)vive, (re)existe e (in)surge nos currículos de escolas básicas com baixo IDEB.

\section{REFERÊNCIAS}

AKKARI Abdeljalil; SANTIAGO, Mylene Cristina. Diferenças na educação: do preconceito ao reconhecimento. Revista Teias, v. 16, n. 40, p. 28-41, 2015.

CANDAU, Vera Maria. Cotidiano escolar e práticas interculturais. Cadernos de Pesquisa, v. 46 n.161 p. 803-820 jul./set. 2016.

CANDAU, Vera Maria. Diferenças culturais, cotidiano escolar e práticas pedagógicas. Revista Currículo Sem Fronteiras, v. 11, n. 2, p. 240-255, jul./dez. 2011.

CANDAU, Vera Maria. Direitos humanos, educação e interculturalidade: as tensões entre igualdade e diferença. Revista Brasileira de Educação, v. 13 n. 37 jan./abr. 2008.

CARVALHO, Carlos Roberto de; PLETSH. Entrevista por uma escola que reconheça as diferentes culturas presentes em seu contexto. Revista Teias, v. 12, n. 24, p. 279-284, jan./abr. 2011.

CASTRO-GÓMEZ, Santiago; GROSFOGUEL, Ramón (editores). El giro decolonial: reflexiones para una diversidad epistémica más allá del capitalismo global. Bogotá: Siglo del Hombre Editores; Editores; Universidad Central, Instituto de Estudios Sociales Contemporáneos y Pontificia Universidad Javeriana, Instituto Pensar, 2007.

HALL, Stuart. Da diáspora: identidades e mediações culturais. Belo Horizonte: UFMG, 2003.

MOREIRA, Antônio Flavio; SILVA, Tomaz Tadeu. Sociologia e teoria crítica do currículo: uma introdução, In: MOREIRA, Antônio Flavio; SILVA, Tomaz Tadeu (Org.). Currículo, cultura e sociedade. São Paulo: Cortez, 2011, p. 7-37.

OLIVÊNCIA, Juan José Leiva. Princípios pedagógicos de la educaión para la convivência intercultural. In: OLIVENCIA, Juan José Leiva y LÓPEZ, Raquel Barrero (coords.). Interculturalidad y escuela: perspectivas pedagógicas em la consctrucción comunitária de la escuela intercultural. São Paulo: Cortez, 2016. p. 4-66.

PACHECO, José Augusto. Escritos Curriculares. São Paulo: Cortez, 2005.

PAVAN, Ruth; BACKES, José Licínio. O processo de (des)proletarização do professor da educação básica. Revista Portuguesa de Educação, v. 29, n. 2, p. 35-58, 2016.

QUIJANO, Aníbal. Colonialidad del poder y clasificación social. In: CASTRO-GÓMEZ, Santiago; GROSFOGUEL, Ramón (editores). El giro decolonial: reflexiones para una diversidad epistémica 
más allá del capitalismo global. Bogotá: Siglo del Hombre Editores; Editores; Universidad Central, Instituto de Estudios Sociales Contemporáneos y Pontificia Universidad Javeriana, Instituto Pensar 2007, p. 93-126.

QUIJANO, Anibal. Colonialidade do poder, eurocentrismo e América Latina. In: LANDER, Edgar. (Org.). A colonialidade do saber: eurocentrismo e ciências sociais - perspectivas latinoamericanas. Buenos Aires: Clacso, 2005. p. 227-278.

RAMOS, Auara Helena. O lugar da diferença no currículo de educação em direitos humanos. Rio de Janeiro: Quartet/Faperj, 2011.

SANTIAGO, Mylene Cristina; AKKARI, Abdeljalil; MARQUES, Luciana Pacheco. Educação Intercultural: desafios e possibilidades. Petrópolis (RJ): Vozes, 2013.

SANTOMÉ, Jurjo Torres. Currículo escolar e justiça social: o cavalo de troia da educação. Porto Alegre: Penso, 2013.

WALSH, Catherine. Interculturalidad crítica y educación intercultural. In. VIAÑA, Jorge; TAPIAS, Luis; WALSH, Catherine (Orgs.). Construyendo Interculturalidad Crítica. La Paz - Bolívia, Instituto Internacional de Integración del Convenio Andrés Bello, 2010. p. 75-96.

WALSH, Catherine. Pedagogías Decoloniales: Prácticas Insurgentes de resistir, (re)existir e (re)vivir. Serie Pensamiento Decolonial. Editora Abya-Yala. Equador, 2017. 